\section{Effects of trihexyphenidyl on schedule-induced alcohol drinking by rats*}

\author{
J. D. KEEHN \\ Atkinson College, York University, Toronto, Ont., Canada
}

Three rats from the Maudsley reactive strains and three rats from the Maudsley nonreactive strain were trained to barpress with food reinforcement scheduled at fixed intervals of $1 \mathrm{~min}$. With various alcohol concentrations, schedule-induced licking was higher in the nonreactive animals but there was little difference in intake between the strains. Injections of trihexyphenidyl attenuated alcohol consumption by all animals, with $3.0 \mathrm{mg} / \mathrm{kg}$ being the most effective dose.

Chemical control of alcoholism in man has concentrated on drugs, such as disulfirum, that, when combined with alcohol, produce an aversive effect (Weissman \& Koe, 1969). Such drugs are not without danger and, also, require abstinence from alcohol when they are taken. This requirement no longer seems to be necessary in the treatment of alcoholism (Pattison et al, 1968), and, in addition, patients wishing to drink, simply refrain from taking their disulfirum doses.

An alternative way of reducing drinking is by anticholinergic drugs. These were first used to block chemically elicited drinking (Grossman, 1962; Stein, .1963) but were later shown to attenuate pala tability-induced (Matsunaga \& Keehn, 1969) and schedule-induced (Burks \& Fisher, 1970; Keehn \& Nagai, 1969) polydipsia. In all these cases, the fluid consumed was water. The attenuation of rats' consumption of weak saccharinsweetened alcohol solutions by the anticholinergic drug trihexyphenidyl has been reported by Keehn \& Matsunaga (1971), who also showed an optimum dose-response effect with $3.0 \mathrm{mg} / \mathrm{kg}$ of the drug in the case of schedule-induced consumption of water.

The present report is of the effects of trihexyphenidyl (Artane) on schedule-induced drinking of strong unsweetened alcohol solutions by rats that showed different levels of schedule-induced drinking of water. SUBJECTS

Six 130-day-old male rats, three from the 39 th generation of the Maudsley reactive strain and three from the 39 th generation of the

*This study was conducted in the Psychological Laboratories of the University of Birmingham through the courtesy of Professor P. L. Broadhurst. The research was supported partly by the Addiction Research Foundation of Ontario and partly by the Medical Research Council of Canada through Grant MA-4528. The trihex y phenidyl was kindly supplied by the Lederle Division of Cyanamid of Canada Ltd. and Table 1 for alcohol concentrations. drinkometers, and all programming and recording were computer controlled. Number of licks and barpresses were printed out at 1-min intervals.

\section{PROCEDURE}

Daily 100-min experimental sessions were run in which barpresses were reinforced with $45-\mathrm{mg}$ Noyes pellets at fixed intervals of not less than $1 \mathrm{~min}$ (FI $1 \mathrm{~min}$ ). For the first three sessions (Sessions 12-14), a $2.5 \%(\mathrm{v} / \mathrm{v})$ alcohol solution was in the drinking tube. The concentration was increased to $3.5 \%$ (Session 15), $4.5 \%$ (Session 16), 6.5\% (Sessions 17-19), 8.5\% (Session 20). This concentration was continued to the end of the experiment for Animals R1 and R3; the concentration was raised to $10.5 \%$ for the other animals from Session 21, onward. Beginning with Session 18, the animals were deprived of fluid for $20 \mathrm{~h}$ before each experimental session.

Artane injections (IP) began with Session 24 , in doses of $0.0,1.5,3.0$, and $4.5 \mathrm{mg} / \mathrm{kg}$ in a Latin-square design, with two drug-free sessions between each dose. The orders in which the animals received the respective doses were: $R 1$ and $r 4$, 1234; R2 and r5, 2341; R3 and r6, 3412. The 0.0 dose was $0.5 \mathrm{ml}$ of distilled water; all other doses were in this medium and volume and were given immediately before an experimental session.

\section{RESULTS}

Figure 1 shows the numbers of licks emitted by each of the animals in each of the 12 predrug sessions. The higher rates of licking by the nonreactive animals, $r 4, r 5$, and $r 6$, does not necessarily represent a greater preference for alcohol by this strain because they had already licked at a

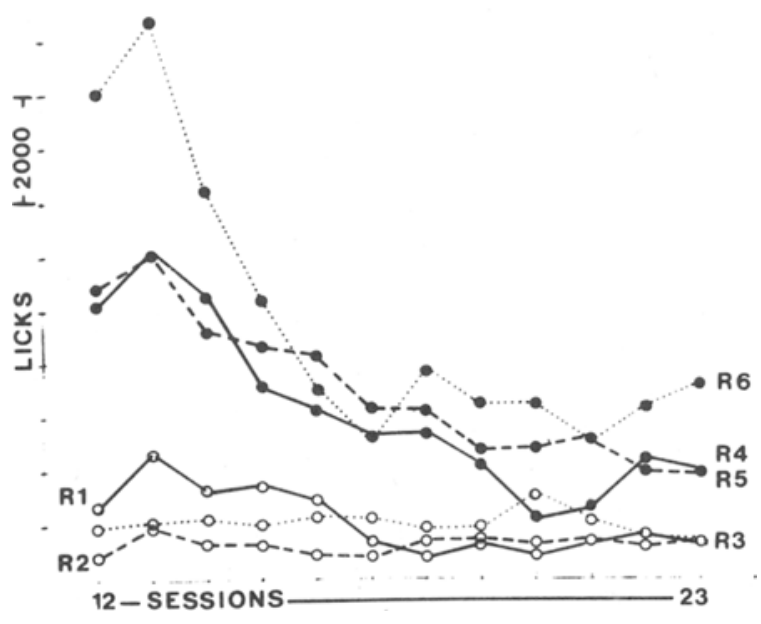

Fig. 1. Number of licks per 100 -min session by reactive $(1,2,3)$ and nonreactive $(4,5,6)$ Maudsley rats food-reinforced at 1 -min intervals. See text 
Table 1

Predrug Alcohol Solution Intakes (Milliliters)

\begin{tabular}{|c|c|c|c|c|c|c|c|c|c|}
\hline Session & 15 & 16 & 17 & 18 & 19 & 20 & 21 & 22 & 23 \\
\hline $\begin{array}{l}\text { Concentration } \\
\text { (Percent) }\end{array}$ & 3.5 & 4.5 & 6.5 & 6.5 & 6.5 & 8.5 & 10.5 & 10.5 & 10.5 \\
\hline R1 & 10 & 13 & 5 & 21 & 7 & 8 & $10^{*}$ & $8^{*}$ & $10^{*}$ \\
\hline R 2 & 8 & 14 & 5 & 13 & 15 & 15 & 20 & 7. & 8 \\
\hline R3 & 10 & 10 & 8 & 11 & 10 & 17 & $10^{*}$ & $8^{*}$ & $8 *$ \\
\hline$r 4$ & 10 & 13 & 8 & 11 & 7 & 5 & 6 & 7 & 7 \\
\hline r5 & 21 & 19 & 12 & 13 & 12 & 12 & 9 & 7 & 7 \\
\hline r6 & 21 & 10 & 8 & 7 & 6 & 7 & 3 & 3 & 5 \\
\hline
\end{tabular}

*Alcohol concentration $8.5 \%(v / v)$

Table 2

Total Barpresses, Licks, and Percent of Intervals in Which Drinks Were Not Taken According to Drug Dose

\begin{tabular}{|c|c|c|c|c|c|c|c|}
\hline Measure & Dose & R1 & $\mathrm{R} 2$ & R 3 & r4 & r5 & $r 6$ \\
\hline Licks & $\begin{array}{l}0.0 \\
1.5 \\
3.0 \\
4.5\end{array}$ & $\begin{array}{l}\mathbf{5 2 4} \\
239 \\
269 \\
\mathbf{4 3 1}\end{array}$ & $\begin{array}{l}492 \\
370 \\
267 \\
415\end{array}$ & $\begin{array}{r}1,235 \\
926 \\
915 \\
1,047\end{array}$ & $\begin{array}{r}1,254 \\
1,369 \\
1,050 \\
706\end{array}$ & $\begin{array}{l}2,512 \\
1,459 \\
1,600 \\
1,620\end{array}$ & $\begin{array}{l}3,373 \\
3,391 \\
2,529 \\
3,971\end{array}$ \\
\hline $\begin{array}{l}\text { Percent } \\
\text { Intervals } \\
\text { Missed }\end{array}$ & $\begin{array}{l}0.0 \\
1.5 \\
3.0 \\
4.5\end{array}$ & $\begin{array}{l}87 \\
82 \\
91 \\
83\end{array}$ & $\begin{array}{l}83 \\
92 \\
69 \\
59\end{array}$ & $\begin{array}{l}72 \\
65 \\
76 \\
72\end{array}$ & $\begin{array}{l}58 \\
62 \\
64 \\
66\end{array}$ & $\begin{array}{r}1 \\
8 \\
31 \\
7\end{array}$ & $\begin{array}{r}5 \\
6 \\
35 \\
1\end{array}$ \\
\hline Barpresses & $\begin{array}{l}0.0 \\
1.5 \\
3.0 \\
4.5\end{array}$ & $\begin{array}{l}3,720 \\
5,501 \\
8,610 \\
3,670\end{array}$ & $\begin{array}{l}7,608 \\
4,194 \\
6,961 \\
9,007\end{array}$ & $\begin{array}{l}3,755 \\
3,494 \\
2,032 \\
2,297\end{array}$ & $\begin{array}{l}2,455 \\
2,295 \\
2,732 \\
1,907\end{array}$ & $\begin{array}{l}3,799 \\
2,886 \\
3,700 \\
4,903\end{array}$ & $\begin{array}{l}1,165 \\
1,176 \\
1,148 \\
1,415\end{array}$ \\
\hline
\end{tabular}

higher rate for water than had the reactives, the respective totals being $6,600,5,511$, and 10,299 licks in a prealcohol session, against $1,338,166$, and 1,055 by $\mathrm{R} 1, \mathrm{R} 2$, and R3, respectively. In fact, beginning with the session in which they were first run water-deprived (Session 18), alcohol intakes were generally higher in the reactive animals (see Table 1 ), even though their licks were fewer. At the highest dose levels, animals were generally flaccid at the end of experimental sessions and exhibited impaired placing responses in that only one paw was raised as they were nosed towards a table edge.

Effects of Artane on numbers of barpresses and licks and on the percentage of interpellet intervals in which drinking failed to occur are shown in Table 2. The drug seemed to have no systematic effect on barpressing, but, for most animals, both measures of drinking were maximally affected by the $3.0 \mathrm{mg} / \mathrm{kg}$ dose of the drug. Cumulative records of licking at the 0.0 and $3.0 \mathrm{mg} / \mathrm{kg}$ doses are shown for all animals in Figs. 2 and 3. (Note that the ordinates of the figures differ by a factor of 5.) The figures show reduced licking by all animals under the drug and, also, distinctly different patterns of drinking by members of the two strains; the nonreactives tended to take small and frequent drinks, whereas the reactives drank infrequently but in fairly regular bursts.

\section{DISCUSSION}

As with schedule-induced water drinking (Keehn \& Matsunage, 1971), schedule-induced alcohol drinking by rats was attenuated by injections of trihexyphenidyl, with $3.0 \mathrm{mg} / \mathrm{kg}$ appearing again to be the optimum dose. The degree of attenuation, about $32 \%$ across all animals, approximated that previously obtained with water;, although alcohol intakes in the absence of the drug were only about one-quarter of those of water.

Although several studies have shown that trihexyphenidyl and other

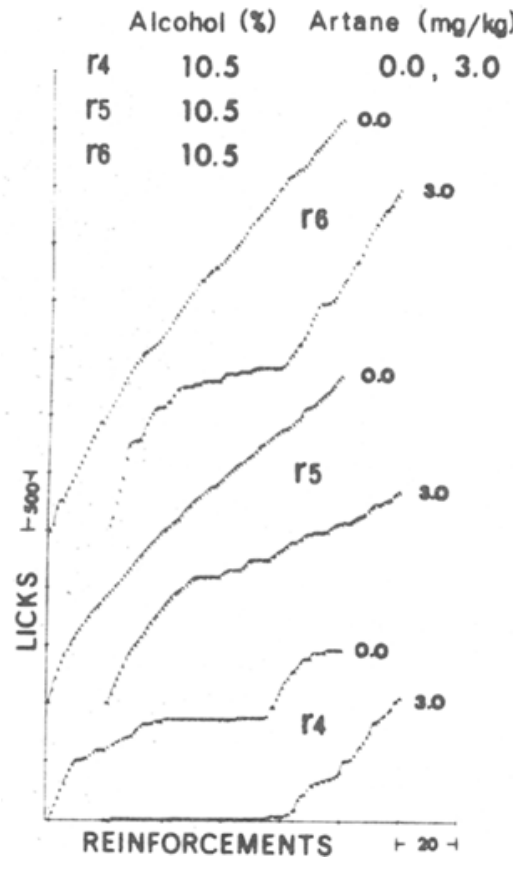

Fig. 2. Cumulative licking records of Maudsley nonreactive rats under $\mathbf{0 . 0}$ and $3.0 \mathrm{mg} / \mathrm{kg}$ Artane doses.

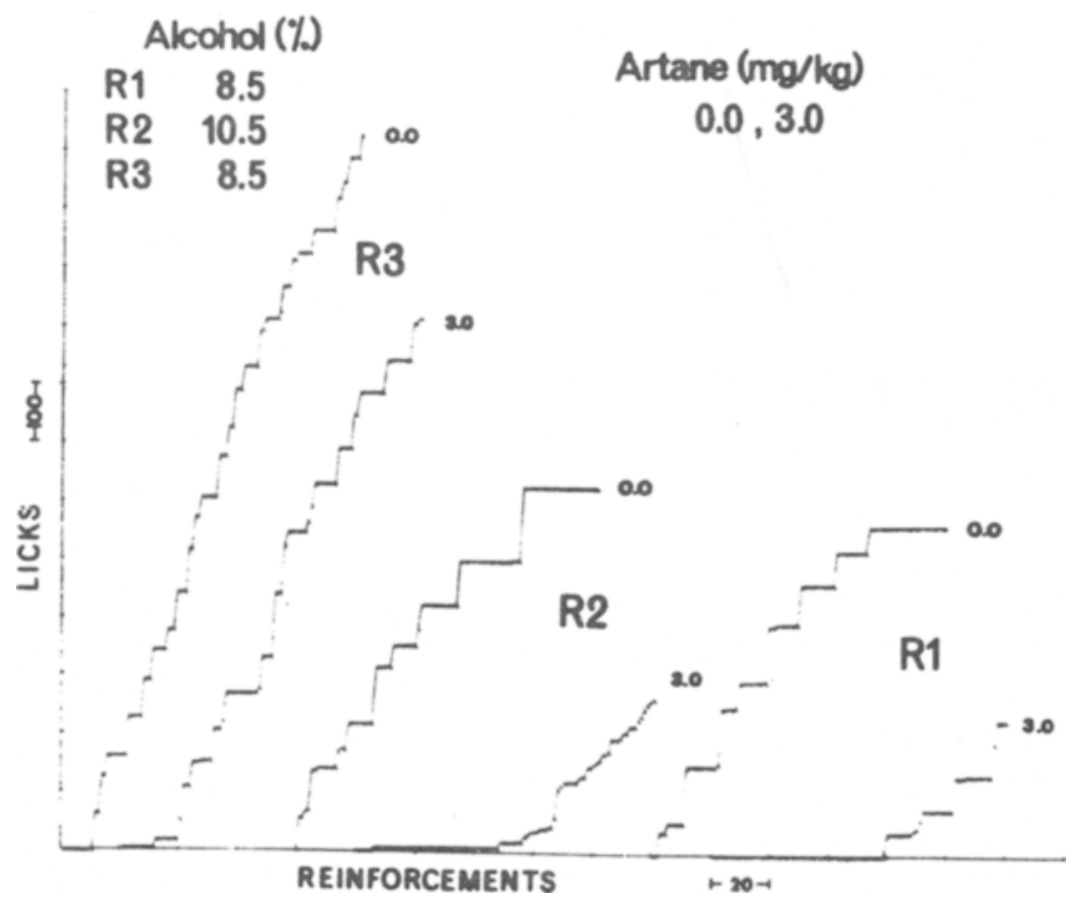

Fig. 3. Cumulative licking records of Maudsley reactive rats under 0.0 and $3.0 \mathrm{mg} / \mathrm{kg}$ Artane doses. Note that the ordinate scale is one-fifth that of Fig. 2 . 
anticholinergic drugs attenuate fluid intake, their mode of action is unclear in that quarternary forms that do not have central action appear to be as effective as tertiary amine forms of the chemical that do (Burks \& Fisher, 1970 ; Matsunaga, personal communication). It is also moot whether the drug acts directly on the behavior of licking or whether its effect is on motivational rather than behavioral mechanisms. But it does appear to be capable of attenuating alcohol intakes without involving the nauseating effects of other chemical deterrents of alcohol drinking, regardless of whether the Ss do (nonreactives) or do not (reactives) exhibit high levels of schedule-induced licking behavior.

\section{RURKS, REFERENCES} Anticholiner \& FISHER, A. E schedule-induced polydipsia. Physiology \& Behavior, 1970, 5, 635-640.

GROSSMAN, S. P. Effects of adrenergic and cholinergic blocking agents on bypothalamic mechanisms. American Journal of Physiology, 1962, 202 , 1230-1236.

KEEHN, J. D., \& MATSUNAGA, M. Attenuation of rats' alcohol consumption by trihexyphenidyl. Paper presented at the International Symposium on Biological Aspects of Alcohol Consumption, Helsinki, 1971.

KEEHN, J. D., \& NAGAI, M. Attenuation of schedule-induced polydipsia by trihexyphenidyl. Psychonomic Science, $1969,15,61-62$.

MATSUNAGA, M. \& KEEHN, J. D Attenuation of palatability-induced polydipsia by biperiden hydrochloride. Psy chonomic Science, 1969, 17, 9-10.

PATTISON, E. M., HEADLEY, E. B.. GLASER, G. C., \& GOTTSCHALK, L. A. Abstinence and normal drinking; an assessment of changes in drinking patterns in alcoholics after treatment. Quarterly Journal of Studies in Alcohol, $1968,29,610-633$

STEIN, L. Anticholinergic drugs and the central control of thirst. Science, 1963 , 139,4648 .

WEISSMAN, A., \& KOE, B. K. Drugs and the deterrence of alcohol consumption. In C. K. Cain (Ed.), Annual reports in medicinal chemistry, 1968. New York: Academic Press, 1969 